\title{
PENGARUH BRAND EXPERIENCE DAN BRAND IMAGE TERHADAP BRAND LOYALTY PADA PELANGGAN BONCABE DI JAKARTA: CUSTOMER SATISFACTION SEBAGAI VARIABEL MEDIASI
}

\author{
Cindy Irawati \\ Program Studi Magister Manajemen Universitas Tarumanagara \\ irawati.cindy@gmail.com
}

Masuk : 11-05-2020, revisi : 24-06-2020 diterima untuk diterbitkan : 25-06-2020

\begin{abstract}
The purpose of this study is to explore the effect of Brand Experience, Brand Image, Customer Satisfaction on Brand Loyalty for BonCabe customers in Jakarta. Variables used are Brand Experience, Brand Image, Customer Satisfaction, Brand Loyalty. This is a descriptive research that use non-probabilistic sampling method ( 240 data closed-questions questionnaires, 7 scale of Likert, compiled in 2019-2020 from BonCabe customers in Jakarta). The data analysis technique is using SEM (Structural Equation Model) methodology (using software: Partial Least Square 3) with $\alpha=0,05$. The results are: (1) a) brand experience and b) brand image has a significant and positive effect toward customer satisfaction of BonCabe in Jakarta. (2) a) brand experience and b) brand image has a significant and positive effect toward brand loyalty of BonCabe in Jakarta. (3) customer satisfaction has a significant and positive effect toward brand loyalty of BonCabe in Jakarta. (4) customer satisfaction could mediate a) brand experience and b) brand image so that they have significant and positive effect toward brand loyalty of BonCabe in Jakarta.
\end{abstract}

Abstrak : Penelitian ini bertujuan untuk mengetahui pengaruh Brand Experience, Brand Image, Customer Satisfaction terhadap Brand Loyalty pada produk bernama BonCabe di wilayah Jakarta. Variabel yang digunakan adalah Brand Experience, Brand Image, Customer Satisfaction, Brand Loyalty. Data yang digunakan adalah data yang dikumpulkan di tahun 2019-2020. Teknik pengumpulan data menggunakan kuesioner tertutup 7 skala Likert, yang menggunakan metode SEM (Structural Equation Model) diolah menggunakan software PLS (Partial Least Square 3) dengan nilai $\alpha=0,05$. Hasil analisis menyimpulkan bahwa (1) Terdapat pengaruh a) brand experience dan b) brand image terhadap customer satisfaction BonCabe di Jakarta. (2) Terdapat pengaruh a) brand experience dan b) brand image terhadap brand loyalty BonCabe di Jakarta. (3) Terdapat pengaruh customer satisfaction terhadap brand loyalty BonCabe di Jakarta. (4) Terdapat customer satisfaction yang dapat memediasi pengaruh a) brand experience dan $b$ ) brand image terhadap brand loyalty BonCabe di Jakarta.

Keywords : Brand Experience, Brand Image, Customer Satisfaction, Brand Loyalty, BonCabe

\section{PENDAHULUAN \\ Latar Belakang}

BonCabe adalah salah satu pelopor merek yang memberikan inovasi untuk merubah mindset orang Indonesia yang terbiasa menggunakan sambal (pasta) menjadi sambal tabur; dengan tujuan agar lebih praktis. BonCabe merupakan produk nomor satu pada kategori TOP Brand 2018 dan 2019; sehingga pesaing baru adalah ancaman bagi BonCabe. Keberhasilan ini tidak terlepas dari peranan pelanggan. Pelanggan bisa dengan mudah meninggalkan sebuah merek apabila tidak memiliki rasa keterikatan yang kuat, padahal pendapatan paling besar dihasilkan oleh pelanggan yang sudah setia dan melakukan pembelian kembali secara rutin. Berdasarkan alasan ini, maka brand loyalty merupakan parameter penting untuk dijadikan dasar analisis menentukan strategi manajemen. 
Beberapa faktor yang memengaruhi brand loyalty yang diuraikan pada penelitian sebelumnya: (1) Penelitian oleh Brakus et al. (2009) menunjukan bahwa brand experience akan memiliki pengaruh positif terhadap loyalty jika dimediasi oleh brand personality dan consumer satisfaction; dan (2) Customer satisfaction diketahui dapat memediasi brand image kepada brand loyalty (Cassia et al., 2017).

\section{Tujuan Penelitian}

1. Untuk mengetahui pengaruh brand experience dan brand image terhadap customer satisfaction BonCabe di Jakarta.

2. Untuk mengetahui pengaruh brand experience dan brand image terhadap brand loyalty BonCabe di Jakarta.

3. Untuk mengetahui pengaruh customer satisfaction terhadap brand loyalty BonCabe di Jakarta.

4. Untuk mengetahui pengaruh mediasi customer satisfaction pada brand experience dan brand image terhadap brand loyalty BonCabe di Jakarta.

\section{TINJAUAN PUSTAKA}

Brand loyalty adalah salah satu dari kunci perilaku pelanggan yang membawa keuntungan (Brakus et al., 2009). Paradigma bisnis telah bergeser dari akuisisi pelanggan ke retensi pelanggan. Loyalitas didapat dari proses psikologi yang melibatkan komponen perilaku (pembelian berulang) dan sikap (komitmen); sehingga berujung pada tindakan baik seperti pembelian berulang, word of mouth positif, dan rujukan; meskipun banyak usaha yang dilakukan kompetitor untuk mengubah pendirian tersebut (Moreira et al., 2017). Beberapa faktor yang mempengaruhi antara lain: (1) Brand experience adalah pengalaman subjektif yang dirasakan pelanggan secara menyeluruh karena paparan pemasaran pada pelanggan yang sangat luas; dari periklanan sampai pengalaman konsumsi produk atau jasa sesungguhnya (Moreira et al., 2017). (2) Brand image adalah persepsi pelanggan akan sebuah merek; baik ketika konsumen memikirkan dan merasakan merek tersebut; yang dapat menjadi sebuah modal tak berwujud karena dapat membantu menambah keunggulan kompetitif perusahaan di pasar (Hapsari, 2018). (3) Customer satisfaction adalah penilaian akhir pelanggan; baik dari segi ekspektasi, perasaan, ataupun nilai guna barang atau jasa setelah melakukan perbandingan antara pengalaman sebelum dan sesudah konsumsi (Minh Ly \& Loe, 2017). Berdasarkan hal di atas, kerangka pemikiran teoritis yang diajukan dalam penelitian ini adalah sebagai berikut:

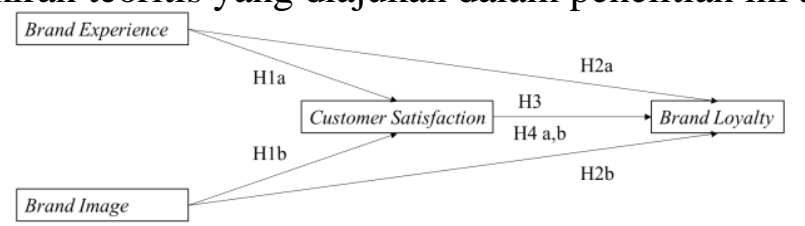

\section{Gambar 1 \\ Model Penelitian}

\section{METODE PENELITIAN}

Desain penelitian yang digunakan adalah metode deskriptif; dengan jenis penelititian one-shot atau cross-sectional studies. Metode sampling yang dipilih adalah nonprobability sampling; yaitu dengan menggunakan convenience atau accidental sampling (Sekaran \& Bougie, 2016). Periode penelitian adalah dari Februari 2019 sampai Juni 2020. Sumber data yang digunakan adalah data primer (menggunakan tipe closed question kuesioner: 7 skala Likert). Populasi dari penelitian ini adalah seluruh masyarakat di Jakarta yang merupakan pelanggan BonCabe. Jakarta dipilih karena merupakan ibukota Indonesia dimana data kependudukannya menunjukan ragam etnis. Berdasarkan Ghozali dan Latan (2015), sampel sebanyak 30-100 sudah cukup untuk penelitian menggunakan metode PLS. 240 sampel yang diisi oleh masyarakat Jakarta terbilang mencukupi jumlah sampel minimum untuk analisa penelitian ini, baik secara jumlah maupun keragaman. 


\section{Operasional Variabel}

(1) Brand Experience adalah pengalaman subjektif yang dirasakan pelanggan secara menyeluruh karena paparan pemasaran pada pelanggan yang sangat luas; dari periklanan sampai pengalaman konsumsi produk atau jasa sesungguhnya (Brakus, et al., 2009). (2) Brand Image adalah persepsi pelanggan akan sebuah merek; baik ketika konsumen memikirkan dan merasakan merek tersebut; yang dapat menjadi sebuah modal tak berwujud karena dapat membantu menambah keunggulan kompetitif perusahaan di pasar (Kaplan, 2007). (3) Customer Satisfaction adalah penilaian akhir pelanggan; baik dari segi ekspektasi, perasaan, ataupun nilai guna barang atau jasa setelah melakukan pembelian atau konsumsi barang/jasa (Brakus et al., 2009; Cassia et al., 2017). (4) Brand Loyalty adalah komitmen yang dimiliki pelanggan untuk tetap setia memilih brand utama, yang ditandai dengan melakukan pembelian berulang; meskipun banyak usaha yang dilakukan kompetitor untuk mengubah pendirian tersebut (Brakus et al., 2009; Cassia et al., 2017; Minh Ly \& Loe, 2017).

\section{HASIL ANALISIS DAN PEMBAHASAN}

Teknik analisis data yang digunakan dalam penelitian ini adalah dengan partial least squares (PLS) - Structural Equation Modeling (SEM) dengan bantuan software PLS versi 3. Evaluasi Outer Model harus dilakukan lebih dulu guna untuk mengetahui apakah data yang telah dikumpullkan memenuhi persyaratan reliabilitas dan validitas (konvergen \& diskriminan), sehingga hasil olah data memiliki kesimpulan yang benar (Sekaran \& Bougie, 2016). Kemudian dilanjutkan dengan Evaluasi Inner Model untuk menunjukan bahwa variabel sudah melambangkan model penelitian dengan baik. Beberapa uji tersebut antara lain: (1) Uji $\mathrm{R}^{2}$ atau Koefisien Determinasi (KD), (2) Uji $\mathrm{Q}^{2}$, (3) Goodness of Fit index (GoF), (4) Uji $\mathrm{F}^{2}$, dan (5) Path Coefficient yang dilanjutkan dengan uji hipotesis.

Analisa koefisien jalur mewakili hubungan hipotesis yang menghubungkan konstruk. Variabel brand experience, brand image, dan customer satisfaction memiliki nilai positif signifikan berpengaruh pada brand loyalty; sehingga dilanjutkan dengan independent t-test dapat digunakan untuk menguji signifikansi perbedaan koefisien jalur antara segmen. Nilai signifikan didapat apabila t-statistik $>t$ value (Hair Jr et al., 2014). Uji hipotesis dilakukan dengan menggunakan taraf signifikansi $5 \%(\alpha=0,05)$ 2-tailed dan menggunakan tingkat kepercayaan 95\%, maka nilai batas minimum dari nilai t-statistik yang digunakan adalah sebesar 1,96 dan hipotesis akan dinyatakan diterima jika memiliki nilai t-statistik lebih dari nilai tersebut. Tabel dibawah ini menunjukan hasil pengujian hipotesis penelitian.

Tabel 1

Rangkuman Total \& Specific Effects

\begin{tabular}{|l|l|l|l|}
\hline & $\begin{array}{l}\text { T Statistics } \\
(|\mathrm{O} / \mathrm{STDEV}|)\end{array}$ & P Values & Keterangan \\
\hline Brand Experience $\rightarrow$ Brand Loyalty & 4,491 & 0 & tidak ditolak \\
\hline Brand Experience $\rightarrow$ Customer Satisfaction & 4,772 & 0 & tidak ditolak \\
\hline Brand Image $\rightarrow$ Brand Loyalty & 10,635 & 0 & tidak ditolak \\
\hline Brand Image $\rightarrow$ Customer Satisfaction & 12,778 & 0 & tidak ditolak \\
\hline Customer Satisfaction $\rightarrow$ Brand Loyalty & 4,67 & 0 & tidak ditolak \\
\hline $\begin{array}{l}\text { Brand Experience } \rightarrow \text { Customer Satisfaction } \rightarrow \text { Brand } \\
\text { Loyalty }\end{array}$ & 3,677 & 0 & tidak ditolak \\
\hline $\begin{array}{l}\text { Brand Image } \rightarrow \text { Customer Satisfaction } \rightarrow \text { Brand } \\
\text { Loyalty }\end{array}$ & 4,132 & 0 & tidak ditolak \\
\hline
\end{tabular}

\section{Pembahasan}

\section{$\mathrm{H}_{1 \mathrm{a}}$ : Adanya pengaruh positif brand experience terhadap customer satisfaction}

Hal ini menunjukan semakin besarnya dan uniknya pengalaman yang dialami oleh konsumen, maka kepuasan yang dirasakan oleh konsumen akan meningkat. Hal ini sesuai dengan penelitian terdahulu yang telah dilakukan oleh Brakus et al. (2009), dimana brand experience memiliki pengaruh positif terhadap customer satisfaction dikarenakan pelanggan suka mencari hal-hal baik yang dapat menstimuli diri, baik secara sensori maupun intelek (untuk menghindari rasa bosan). Dalam kasus ini, brand experience yang dialami oleh 
pelanggan antara lain adalah sensasi yang dirasakan oleh alat indera yang dimiliki oleh pelanggan ketika mengkonsumsi produk BonCabe ini. Paduan pengalaman pelanggan dalam menggunakan BonCabe untuk dipadukan dengan makanan lain akan memberikan customer satisfaction karena produk tidak hanya dibeli untuk dikonsumsi, tetapi ada nilai tambah lain yang ditawarkan oleh brand ini; yaitu interaksi dengan tim marketing dan sales. Hal ini diperkuat dengan penelitian Moreira et al. (2017) dan Minh Ly \& Loe (2017) yang menunjukan bahwa customer satisfaction didasari oleh dimensi afektif dari brand experience; sehingga menambah pengetahuan dan kemampuan untuk mengingat produk tersebut ketika digunakan, sehingga akan meningkatkan efisiensi dari kegiatan promosi yang dilakukan oleh perusahaan.

\section{$\mathrm{H}_{1 \mathrm{~b}}$ : Adanya pengaruh positif brand image terhadap customer satisfaction}

Hal ini menunjukan semakin membekasnya brand image dalam benak pelanggan, maka customer satisfaction akan meningkat. Menurut penelitian terdahulu oleh Hapsari (2018) dimana brand image memiliki peran penting dalam memenuhi customer satisfaction karena social media. PT KBU sering mengeluarkan video edukasi kepada pelanggan melalui media sosial sehingga pelanggan bisa memahami bahwa BonCabe dibuat dari cabai pilihan dan diproses secara higienis sehingga memiliki umur masa simpan yang baik; ditambah dengan nilai "kepraktisan" dimana pelanggan tidak perlu membeli dan mengolah cabai sendiri. Hal ini menjadi daya tarik yang membuat pelanggan puas dan sesuai dengan gaya hidup "instan". Persepsi pelanggan terhadap BonCabe: berfungsi sesuai dengan ekspektasi (memberikan sensasi pedas) dengan harga dan kualitas yang sesuai. Berdasarkan penelitian Cassia et al. (2017), brand image mempengaruhi kepuasan karena membentuk harapan pelanggan sebelum mereka melakukan pembelian. Memori akan BonCabe yang telah popular tersebut menyebabkan pelanggan memiliki kecenderungan untuk memilih kembali BonCabe.

\section{$\mathrm{H}_{2 \mathrm{a}}$ : Adanya pengaruh positif brand experience terhadap brand loyalty}

Hal ini menunjukan semakin besarnya dan uniknya pengalaman yang dialami oleh konsumen, maka loyalitas konsumen akan meningkat. Hal ini sesuai dengan penelitian terdahulu oleh Brakus et al., (2009) dan Nyohardi (2016) dimana brand experience akan mendorong pelanggan untuk melakukan pengulangan untuk mendapatkan pengalaman serupa; sehingga akan timbul loyalitas pelanggan. Selain itu, pelanggan seringkali merekomendasikannya kepada orang lain, dan kecil kemungkinan untuk membeli merek lain. Penelitian Hussein (2018) menunjukan bahwa di dalam kultur budaya timur, para pelanggan memiliki kecenderungan untuk menghindari risiko; dimana pelanggan akan memilih produk yang sudah memiliki pengalaman positif sebelumnya. Ditambah fakta bahwa brand experience diketahui memiliki pengaruh terhadap afeksi, koneksi, pertimbangan, perilaku, dan gairah pelanggan dalam berperilaku terhadap produk (untuk menilai, bersikap, preferensi terhadap merek, niat beli atau pembelian berulang, dan pengingatan akan produk tersebut) (Brakus $e t$ al., 2009).

\section{$\mathbf{H}_{2 \mathrm{~b}}$ : Adanya pengaruh positif brand image terhadap brand loyalty}

Hal ini menunjukan semakin membekasnya brand image dalam benak pelanggan, maka loyalitas pelanggan akan meningkat. Hal ini sesuai dengan penelitian oleh Cassia et al. (2017), dimana brand image merupakan prediktor yang kuat untuk loyalitas; karena dapat meningkatkan potensi kunjungan kembali dari pelanggan berdasarkan asosiasi pelanggan dari barang/servis yang diberikan oleh brand tersebut. Apalahi jika brand yang sudah dipersepsikan baik di mata pasar (Chinomona, 2016). Persepsi sociable marketing dan resep praktis akan membekas dalam benak pelanggan dan bertahan lama, sehingga muncul keinginan untuk melakukan pembelian berulang (indikator brand loyalty). Asosiasi brand image yang positif dalam benak pelanggan mempermudah pelanggan untuk merasakan interaksi pemilik brand dengan dirinya; sehingga kecenderungan untuk melakukan pembelian kembali dapat lebih terprediksi (Ferdiawan et al., 2018). Oleh karena itu, BonCabe yang sudah menguasai pasar secara dominan dapat dengan mudah merebut hati pelanggan dan mempertahankan loyalitasnya. 


\section{$\mathrm{H}_{3}$ : Adanya pengaruh positif customer satisfaction terhadap brand loyalty}

Hal ini menunjukan bahwa pelanggan yang puas akan loyal pada merek tersebut. Hal ini sesuai dengan penelitian Moreira et al. (2017), dimana pelanggan yang puas akan cenderung memiliki loyalitas dan kecenderungan untuk melakukan pembelian kembali; apalagi ketika didasari karena kualitas produk yang lebih baik daripada kompetitor. BonCabe merupakan produk unggulan karena produk lebih awet dibandingkan sambal biasa (sampai 2 tahun) dan lebih pedas. Sebagai tambahan, penelitian Nyohardi (2016) menunjukan bahwa customer satisfaction memiliki pengaruh positif terhadap brand loyalty karena pelanggan memikirkan keunggulan produk dan pengalaman yang didapatkan ketika mengkonsumsinya. Selain kualitas, BonCabe memberikan kepraktisan, sehingga cocok untuk gaya hidup instan, karena BonCabe bisa dikonsumsi sebagai kondimen dan untuk memasak resep lain. Pelanggan yang puas tentunya akan membeli produk kembali untuk memenuhi kebutuhan akan produk tersebut (meski harganya sedikit lebih mahal).

\section{$\mathrm{H}_{4 \mathrm{a}}$ : Customer satisfaction dapat memediasi secara positif pengaruh brand experience terhadap brand loyalty}

Hal ini menunjukan semakin besarnya dan uniknya pengalaman yang dialami oleh pelanggan, ditambah dengan rasa puas yang dirasakan oleh pelanggan, maka pelanggan akan semakin loyal terhadap brand BonCabe. Hal ini sesuai dengan penelitian terdahulu oleh Brakus et al. (2009), dimana brand experience yang positif akan menghasilkan customer satisfaction yang baik; dan akan meninggalkan memori yang baik dalam ingatan pelanggan. Brand experience yang kuat akan menetap pada memori pelanggan yang puas, dan akan memengaruhi keputusan dalam melakukan pembelian kembali, rekomendasi kepada orang lain, dan tidak mencari alternatif lain karena pelanggan dapat mengurangi waktu untuk mempertimbangkan opsi produk (Moreira et al., 2017; Minh Ly \& Loe, 2017). BonCabe memberikan paduan pengalaman bagi pelanggan sehingga tidak mudah dilupakan, ditambah lagi BonCabe adalah perintis. Edukasi pelanggan menggunakan sambal tabur yang merupakan usaha yang sulit. Namun, sebagai produk unik yang berbeda dari produk lainnya, tentunya BonCabe akan membekas pada ingatan. Dengan kualitas produk yang tinggi, mudah bagi pelanggan untuk menceritakan brand BonCabe ini kepada rekan/teman dan famili. Semua langkah positif yang diambil pelanggan adalah bagian dari brand ambassador secara tidak langsung dan merupakan indikator dari brand loyalty.

\section{$\mathrm{H}_{4 \mathrm{a}}$ : Customer satisfaction dapat memediasi secara positif pengaruh brand image terhadap brand loyalty}

Hal ini menunjukan bahwa semakin tingginya persepsi merek yang dialami oleh pelanggan, ditambah dengan rasa puas dari pelanggan, maka pelanggan akan semakin loyal terhadap BonCabe. Hal ini sesuai dengan penelitian oleh Hapsari (2018) dimana brand image dapat menimbulkan halo effect pada customer satisfaction; dimana dapat berpengaruh pada loyalitas pada akhirnya. Pada penelitian ini halo effect yang dimaksud adalah kesan kualitas (atribut dari BonCabe) yang ditimbulkan sebagai akibat dari brand yang sudah besar dan banyak dibicarakan di masyarakat sebagai market leader. Penelitian oleh Ferdiawan et al., (2018) menunjukan bahwa loyalitas memberikan gambaran permintaan produk/jasa (lebih mudah diprediksi) dan juga membantu menciptakan batasan/barrier untuk menyulitkan kompetitor untuk memasuki pasar tersebut. BonCabe sebagai market leader yang memiliki kualitas yang baik memanfaaatkannya sebagai strategi marketing. Hal ini akan membuat calon kompetitor menjadi semakin sulit untuk berkompetisi karena adanya barrier yang muncul dalam benak pelanggan, dimana hal ini lebih sulit untuk dianalisa/direbut.

\section{KESIMPULAN DAN SARAN Kesimpulan}

Kesimpulan yang dapat diambil adalah (1) Terdapat pengaruh a) brand experience dan b) brand image terhadap customer satisfaction BonCabe di Jakarta; (2) Terdapat pengaruh a) 
brand experience dan b) brand image terhadap brand loyalty BonCabe di Jakarta; (3) Terdapat pengaruh customer satisfaction terhadap brand loyalty BonCabe di Jakarta; dan (4) Terdapat customer satisfaction yang dapat memediasi pengaruh a) brand experience dan b) brand image terhadap brand loyalty BonCabe di Jakarta.

\section{Saran}

Beberapa saran yang dapat disampaikan adalah: (1) Perluas wilayah lokasi penelitian menjadi seluruh daerah di Indonesia dan mancanegara untuk mendapatkan masukan terhadap consumer behavior yang berbeda-beda di kalangan masyarakat; (2) Menambah jumlah sampel untuk meningkatkan tingkat validitas dari penelitian ini; dan (3) Melakukan penelitian dengan variabel lain selain brand experience dan brand image yang dimediasi ataupun tidak dimediasi oleh customer satisfaction terhadap brand loyalty pada BonCabe.

\section{DAFTAR PUSTAKA}

Brakus, J. J., Schmitt, B. H., \& Zarantonello, L. (2009). Brand Experience : What is It? How is It Measure? Does It Affect Loyalty? Journal of Marketing, 73, 52-68.

Cassia, F., Cobelli, N., \& Ugolini, M. (2017). The Effect of Goods-Related and Service-Related B2B Brand Images on Customer Loyalty. Journal of Business \& Industrial Marketing, $32(5), 722-732$.

Chinomona, R. (2016). Brand Communication, Brand Image and Brand Trust as antecedents of Brand Loyalty. African Journal of Economic and Management Studies.

Ferdiawan, Y., Hermawan, A., Wardana, L. W., Arief, M., \& Sarbini. (2018). Satisfaction as Effect Mediation of Brand Image and Customer Relationship Management on Customer's Loyalty. The First International Research Conference on Economics and Business (pp. 34-50). KNE Social Sciences.

Ghozali, I., \& Latan, H. (2015). Partial Least Squares Konsep, Teknik dan Aplikasi Menggunakan Program SmartPLS 3.0 Untuk Penelitian Empiris. Semarang : Undip.

Hair Jr, J. F., Sarstedt, M., Hopkins, L., \& Kuppelwieser, V. G. (2014). Partial Least Squares Structural Equation Modeling (PLS-SEM) : An Emerging Tool in Business Research. European Business Review, 26 (2), 106-121.

Hapsari, R. (2018). Creating Educational Theme Park Visitor Loyalty : The Role of Experience-Based Satisfaction, Image, and Value. Journal of Tourism and Hospitality Management, 24 (2), 359-374.

Hussein, A. S. (2018). Effects of Brand Experience on Brand Loyaly in Indonesian Casual Dining Restaurant: Roles of Customer Satisfaction and Brand of Origin. Tourism and Hospitality Management, 24 (1), 119-132.

Kaplan, M. D. (2007). Product Appearance and Brand Knowledge : An Analysis of Critical Relationships. Turkey : Izmir University of Economics.

Minh Ly, P. T., \& Loe, L. T. (2017). The Relationship between Brand Experience, Brand Personallity and Customer Loyalty. International Journal of Business and Economics, 16 (2), 109-126.

Moreira, A. C., Freitas da Silva, P. M., \& Moutinho, V. M. (2017). The Effect of Brand Experiences on Quality, Satisfaction and Loyalty : An Empirical Study in the Telecommunications Multiple-play Service Market. Revista Innovar Journal, 27 (64), Abril-Junio.

Nyohardi, P. (2016). Pengaruh Brand Experience terhadap Brand Loyalty melalui Brand Satisfaction dan Brand Attitude. Jurnal Bisnis dan Manajemen, 52 (11), 159-184.

Sekaran, U., \& Bougie, R. (2016). Research Methods for Business. Chichester, West Sussex, United Kingdom : John Wiley \& Sons Ltd. 